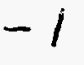

\section{LUBRICANT MONITORING USING QUARTZ RESONATOR SENSORS *}

\author{
R. W. Cernosek, S. J. Martin, J. J. Spates ${ }^{+}$, A. N. Rumpf ${ }^{+}$ \\ and $K O$. Wessendorf \\ Sandia National Laboratories, Albuquerque, NM 87185
}

A thickness shear mode (TSM) resonator consists of metal electrodes deposited on opposite faces of a thin AT-cut quartz crystal. An RF voltage applied between the electrodes excites a shear mode mechanical resonance when the excitation frequency matches the crystal resonant frequency (Fig. 1). Any material in contact with the quartz surface perturbs the shear mode resonance. Rigid mass layers move synchronously with the surface reducing the electrical operating resonant frequency according to [1]

$$
\Delta f_{s} \cong-\frac{2 f_{s}^{2} n}{N \sqrt{\mu_{q} \rho_{q}}} \rho_{s},
$$

where $f_{s}$ is the series resonant frequency, $n$ is the number of surfaces contacted, $\mathrm{N}$ is the resonator harmonic number (odd integers), $\mu_{q}$ and $\rho_{q}$ are the quartz shear stiffness and density, and $\rho_{s}$ is the surface mass density. Liquids are viscously entrained by the quartz surface, producing both a resonant frequency shift and resonance damping (decrease in amplitude) [2]:

and

$$
\Delta f_{s}=-\frac{f_{s}}{2}\left[1+\frac{N}{2 n} \sqrt{\frac{\pi \mu_{q} \rho_{q}}{f_{s} \rho \eta}}\right]^{-1}
$$

$$
\Delta R=\frac{n N}{8 K^{2} C_{0}} \sqrt{\frac{\pi \rho \eta}{f_{s} \mu_{q} \rho_{q}}},
$$

where $\rho$ and $\eta$ are the liquid density and viscosity, $K^{2}$ is the quartz electromechanical coupling factor, and $C_{0}$ is the static resonator capacitance. These shifts in resonant parameters can be measured using network analysis or simpler oscillator electronics.

The ability to monitor real-time changes in fluid density and viscosity and the accumulation of particulates or precipitates makes the quartz resonator sensors ideal for in situ lubricant diagnostics, field screening, and vehicle applications. Resonators and accompanying electronics are small and inexpensive and can survive in extreme temperature, vibration, and chemical environments.

Oscillator Electronics In order to accommodate the large motional resistances of lubricants $(\Delta R>1 \mathrm{k} \Omega)$, a "lever" oscillator circuit has been designed and implemented [3]. This circuit provides two outputs: an RF signal that closely tracks $f_{5}$, and a dc voltage proportional to $\Delta \mathrm{R}$. By actively and variably dividing the resonator impedance (the lever action), the oscillator maintains near-constant phase and loop gain over a wide dynamic range. Recent implementations of the circuit demonstrated single-sided $(n=1)$ operation in oils with viscosity greater than $1000 \mathrm{cP}$.

Oil Viscosity Monitoring Oil viscosity determination is important in product formulation and in characterization of lubricating quality during use. In vehicles, oil viscosity increases due to oxidation at high temperatures and pressures and decreases due to fuel or water dilution. Proper viscosity indication aids in maintenance. We have shown that quartz resonator lubricant monitors [4] compare favorably with standard techniques for determining oil viscosity and viscosity index [5].

* This work was performed at Siandia National L aboratories supported by the U.S. Dept. of lincrey under comtract No. DI:-ACO4-94AL,8500\%.

On contract from Kicch Compration, AlbuqutequL, NM.

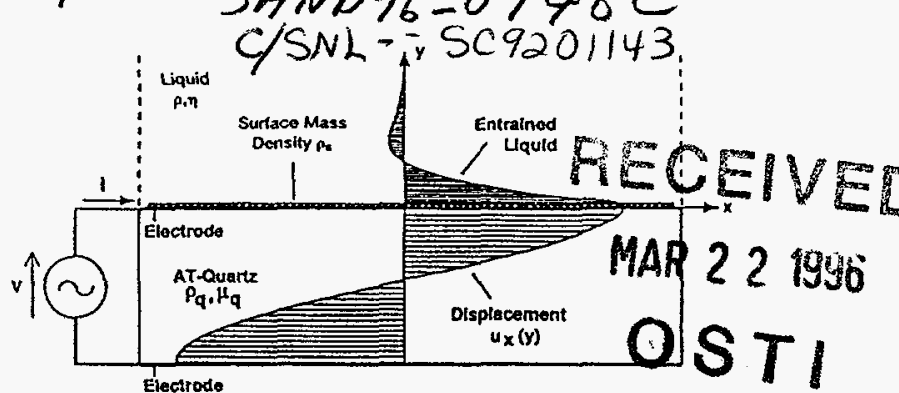

Fig. 1. Cross-sectional view of a TSM resonator.

Resonator measurements cannot yet approach the accuracy and precision of standard techniques (approximately $5 \%$ compared to $<1 \%$ ), but their in situ operation provides for a real-time diagnostic.

Non-Newtonian Characterization The viscosities of most lubricating oils exhibit shear-rate dependence. The quartz resonator can be used to interrogate some of these non-Newtonian aspects of lubricants by measuring the shift in resonator stored energy (motional reactance, $\Delta \mathrm{X}$, related to $\Delta f$ ) relative to the resonator dissipated power ( $\Delta R$ ). For a Newtonian fluid, $\Delta X \equiv \Delta R$. If the contacting liquid is described as a Maxwell fluid whose viscosity exhibits a relaxation response with frequency [6]: $\eta=\eta_{0} /(1+j \omega \tau)$, where $\eta_{0}$ is the low-frequency viscosity and $\tau$ is the fluid relaxation time defined by $\tau=\eta_{0} / \mu$, for $\mu$ the high frequency shear modulus; then $\Delta R>\Delta X$. This property is illustrated in Fig. 2 for two synthetic lubricants: a synthetic base stock and its fully-formulated oil. The polymeric additives in the fully-formulated lubricant produce greater non-Newtonian character as indicated by the larger deviations between motional parameters at the low temperatures.

Cloud Point Detection The critical temperature in crude oil products where the high molecular weight hydrocarbons start to precipitate or visibly crystallize is known as the cloud point. A quartz resonator sensor has been used to quantify this feature in several different oils [7]. An abrupt increase in resonator frequency and resonance damping is measured at the cloud point as the temperature of the oils is slowly decreased. This precise indicator correlates well with the visibly-observed cloud point. As demonstrated in these tests, abrupt shifts in resonant frequency and damping are often the result of phase changes in the contacting material. These characteristics of the quartz resonator sensors can be exploited to determine other lubricant properties.

[1] G. Sauerbrey, Z Phys., 155, 206-222 (1959).

[2] S.J. Martin, et.al., Anal. Chem., 63, 2272-2281 (1991).

[3] KO. Wessendorf, Proc IEEE Inth. Freq. Control Symp., 711-717 (1993).

[4] RW. Cernosek, et.al., Proc Sensors Expo, 527-539 (1994).

[5] ASTM, Annual Handbbook of ASTM Standards, D445 \& D341 (1994).

[6] F.M. White, Viscous Fluid Flow (McGraw-Hill, NY, 1991).

[7] J.J. Spates, et.al., Proc ACS Fuel Chem. Symp., Chicago, IL (1995).

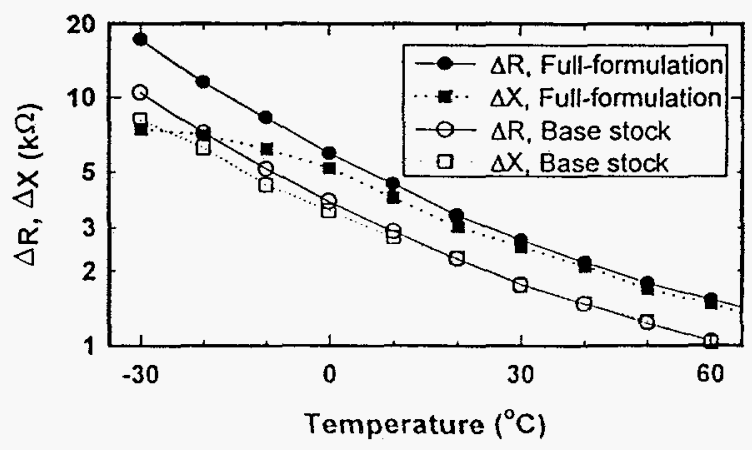

Fig. 2. Motional resistance (AR) and reactance ( $\Delta \mathrm{X})$ versus temperature for two symthetic lubricants. 


\section{DISCLAIMER}

This report was prepared as an account of work sponsored by an agency of the United States Government. Neither the United States Government nor any agency thereof, nor any of their employees, makes any warranty, express or implied, or assumes any legal liability or responsibility for the accuracy, completeness, or usefulness of any information, apparatus, product, or process disclosed, or represents that its use would not infringe privately owned rights. Reference herein to any specific commercial product, process, or service by trade name, trademark, manufacturer, or otherwise does not necessarily constitute or imply its endorsement, recommendation, or favoring by the United States Government or any agency thereof. The views and opinions of authors expressed herein do not necessarily state or reflect those of the United States Government or any agency thereof. 


\section{DISCLAMMER}

Portions of this document may be illegible in electronic image products. Images are produced from the best available original document. 